\title{
FACEBOOK COMO AMBIENTE DE APRENDIZAGEM COLABORATIVA NA DISCIPLINA DE BANCO DE DADOS
}

\author{
Patrícia Iuly de Castro de Souza ${ }^{1}$, Claudiany Calaça de Sousa ${ }^{2}$, Rogério Pereira de \\ Sousa $^{3}$, Ramásio Ferreira Melo ${ }^{4}$. \\ ${ }^{1}$ Graduada em Licenciatura em Computação - IFTO, Campus Araguatins. \\ ${ }^{2}$ Acadêmica de Licenciatura em Computação - IFTO, Campus Araguatins. \\ ${ }^{3}$ Mestre em Engenharia de Produção e Sistemas (UNISINOS) - Professor do IFTO, \\ Campus Araguatins. \\ ${ }^{4}$ Mestre em Educação (UFSM) - Professor do IFTO, Campus Araguatins.
paty yule@hotmail.com, claudianydesousa@gmail.com, \{ramasiomelo,ro gerio.pereira\} difto.edu.br

Resumo. Este artigo tem por objetivo analisar o potencial do trabalho colaborativo mediado pelo Facebook, a partir da criação de um grupo privado, com alunos do Curso Técnico em Redes de Computadores no IFTO - Campus Araguatins, na disciplina de Banco de Dados. Foi adotada uma abordagem metodológica quanti-qualitativa, de caráter exploratório na forma de pesquisa-ação, que objetiva explorar a conduta dos alunos perante a realização de atividades utilizando o Facebook, a fim de, entender como esse espaço pode favorecer a aprendizagem colaborativa. Os resultados possibilitam analisar positivamente o quanto os alunos conseguiram colaborar, partilhar e interagir uns com os outros de forma ativa, concluindo que o uso planejado das redes sociais no processo educativo impulsiona a construção crítica e reflexiva de conhecimentos.

Palavras-chave: Ensino aprendizagem, Colaboração, Facebook.

\section{FACEBOOK AS A COLABORATIVE LEARNING ENVIRONMENT IN THE DATABASE DISCIPLINE}

\begin{abstract}
This article aims to analyze the potential of the collaborative work mediated by Facebook, from the creation of a private group, with students of the Technical Course in Computer Networks at the IFTO - Campus Araguatins, in the Database discipline. A quantitative-qualitative methodological approach was adopted, with an exploratory character in the form of action research, which aims to explore the students' behavior in the performance of activities using Facebook, in order to understand how this space can favor collaborative learning. The results allow a positive analysis of how students have been able to collaborate, share and interact with one another actively, concluding that the planned use of social networks in the educational process boosts the critical and reflexive construction of knowledge.
\end{abstract}

Keywords: Teaching learning, Collaboration, Facebook.

\section{INTRODUÇÃO}

A Sociedade vivência a evolução das Tecnologias de Informação e Comunicação (TICs), caracterizada pelo acesso rápido as informações empenham-se em permitir a 
colaboração, interatividade e produção de conhecimento, possibilitando a alteração do meio construindo uma sociedade crítica e participativa.

Este cenário comunicacional, vêm atraindo a atenção de milhares de usuários da internet, chegando a atingir diversas esferas, como econômica, científica, educacional, cultural, entre outras. Nesse panorama, as redes sociais web são alvos de estudo como ferramenta facilitadora dos processos ligados ao conhecimento através da produção colaborativa.

O espaço escolar deve estar aberto para esse tipo de produção, buscar uma educação construtiva e enriquecer o processo de ensino-aprendizagem com a integração de diferentes tecnologias que potencializam a colaboração. Portanto, considera-se como uma ação construtivista o trabalho em conjunto dos professores e alunos que agregam temas educacionais aos seus conteúdos publicados nas redes sociais para discutir, construir e adquirir novos conhecimentos.

As redes sociais possibilitam o compartilhamento de informações, o confronto de ideias e institui um processo colaborativo. A pesquisa adota o Facebook, para analisar os resultados gerados com o compartilhamento de informações e experiências desenvolvidas na disciplina de Banco de dados em uma turma de $2^{\circ}$ ano do Ensino Médio integrado ao curso Técnico em Redes de Computadores do Instituto Federal de Educação, Ciência e Tecnologia do Tocantins (IFTO) - Campus Araguatins.

Desta forma, propomos com este artigo o estudo e debate sobre o potencial das redes sociais como plataformas de colaboração, apresentando ainda apontamentos que analisam, numa perspectiva inovadora, a aprendizagem significativa dentro de um ambiente colaborativo em rede, bem como oferecer ideias e reflexões sobre as transformações na prática escolar e como isso contribui a favor da educação.

\section{REVISÃO BIBLIOGRÁFICA}

\subsection{Redes sociais}

Em decorrência da popularização das redes sociais web, muitas pesquisas são destinadas a estudar a forma de organização da aprendizagem e do trabalho nesse ambiente. Inicialmente, são importantes algumas considerações sobre o termo rede e o início do seu estudo.

"O termo rede tem origem no vocábulo latim rete e assume, hoje em dia diversos significados" (FERREIRA, 2011, p. 210). Seu estudo foi iniciado principalmente por matemáticos, quando o matemático e físico Leonhard Euler em 1976 propôs a solução para o problema da cidade de Konegsberg, atualmente Kaliningrad, na Rússia. A cidade tinha sete pontes e o problema consistia em encontrar um caminho que passasse por todas as pontes uma única vez.

Euler publicou um artigo solucionando o problema das pontes, para tanto ele conectou as quatro partes terrestres (nós ou pontos) com as sete pontes (arestas ou conexões), provando a inexistência desse caminho e de forma não intencional criou $o$ primeiro teorema (Figura 1) da Teoria dos grafos (RECUERO, 2009). 


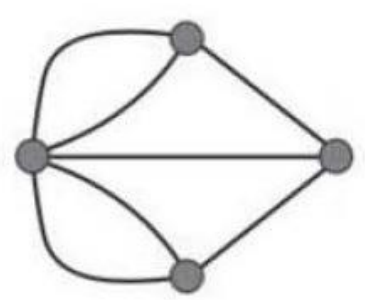

Figura 1 - Primeiro teorema da Teoria dos Grafos. Fonte: Recuero, (2009).

Todo o conhecimento sobre redes teve base na teoria dos grafos (FERREIRA, 2011, p. 210), a partir disso as redes foram estudadas dentro das Ciências e, atualmente, em razão da sua popularidade, são objetos de estudo em diversos ramos do conhecimento.

Para Ferreira (2011, p. 214) o conceito de redes sociais se denomina como "um conjunto de pessoas, com algum padrão de contatos ou interações, entre as quais se estabelecem diversos tipos de relações e, por meio delas, circulam diversos fluxos de informações".

As redes sociais se caracterizam pela liberdade de acesso, comunicação, interação, compartilhamento de conhecimentos e informações em múltiplos suportes que possibilitam a manifestação do pensamento e criação de um espaço favorável à aprendizagem colaborativa.

Segundo Moraes (2011, p.16) as redes sociais oferecem uma variedade de possibilidades para realizar trabalhos escolares, tais como vídeos e imagens, cartazes para eventos, realização de pesquisas e exposição de resultados, dentre outros. No entanto, a utilização desta ferramenta em sala de aula deve estar baseada em um planejamento, procurando estabelecer regras sobre o que será utilizado, como será utilizado e para que será utilizado, de outro modo será apenas uma ferramenta incerta.

Por entender que o conhecimento se constitui dentro e fora do ambiente escolar é fundamental pensar nas redes sociais como espaços que complementem a formação acadêmica dos alunos. Para isso, basta que a escola se coloque como norteadora das ações dos alunos, pois é preciso orienta-los a selecionar as informações e os saberes que estão disponíveis a eles.

\subsection{Facebook como ferramenta mediadora da aprendizagem colaborativa em redes sociais.}

As redes sociais podem ser utilizadas para diversas finalidades, como entretenimento, informativa, profissional e acadêmica, neste último caso essas ferramentas podem auxiliar no processo de aprendizagem.

O Facebook que se tornou a maior rede social do planeta e em virtude de sua popularidade e outros atrativos como o hipertexto, a rápida disseminação de notícias e a incontestável simplicidade em seu uso, a rede social atrai a atenção de pessoas em diversas idades.

Há quem diga que as redes sociais como o Facebook, não são capazes de intermediar o ensino-aprendizagem em qualquer disciplina por não ser um ambiente exclusivamente educacional. Contrapondo-se a esta ideia Moraes (2011, p. 15) enfatiza que,

As redes sociais possuem características que se assemelham aos ambientes virtuais de aprendizagem (AVA), (como por exemplo, o moodle), fóruns, mensagens, chat; e que podem ser utilizados no dia a dia permitindo novas formas de ensino, possibilitando trocas, validando saberes e construindo e 
reinventando práticas pedagógicas através da participação ativa dos envolvidos.

A aprendizagem colaborativa implica num processo aberto de colaboração, onde um grupo trabalha em conjunto para atingir um objetivo comum, essa temática não é nova, porém se tratando da aplicação desta temática no uso das redes sociais é o mais novo enfoque da aprendizagem.

Muitos usuários se organizam em grupos do Facebook. Estes grupos se tornaram espaços virtuais para debates, com o intuito de expor ideias, discussões e disseminar informações, em torno de interesses mútuos.

O Facebook pode abrigar, de forma positiva, ambientes direcionados para o estudo que funcionam como redes de aprendizagem, onde seus membros se relacionem como coautores do processo pedagógico. Para tanto, deve ser criado com intenção de promover o compartilhamento e a interação entre os participantes, gerando crescimento mútuo. E cabe aos educadores testá-las e avaliar a influência dessas ferramentas no processo de ensino.

Costa e Vilaça (2013) declaram que o emprego de páginas e grupos do Facebook como artifício pedagógico é favorável ao aprendizado do estudante, que ao acessar frequentemente e curtir as publicações de seu interesse terá a informação instantaneamente ao seu alcance, possibilitando a fixação de forma natural e interativa. ( p. 818).

Desse modo, integrar o Facebook como espaços de ensino aprendizagem, dentro de uma perspectiva colaborativa, pode ser vantajoso para educação, pois esses grupos de discussão contextualizam novas formas de produção do conhecimento e organização da aprendizagem na qual os alunos estão inseridos.

\section{PROCEDIMENTOS METODOLÓGICOS}

O Estudo foi realizado no contexto da Disciplina de Banco de Dados, que compõe a instância curricular do Curso Técnico em Redes de Computadores no IFTO - Campus Araguatins, com 24 alunos de uma turma do $2^{\circ}$ ano do Ensino Médio, durante os dois semestres do ano de 2015, entre março e dezembro. Foi adotada uma abordagem metodológica quanti-qualitativa, de caráter exploratório na forma de pesquisa-ação.

$\mathrm{O}$ trabalho utilizou a ferramenta Facebook no processo de ensino-aprendizagem que permitiu a definição e configuração de um espaço de aprendizagem colaborativa. Posteriormente, por intermédio da pesquisa-ação estudou-se a utilização do Facebook como ferramenta mediadora na disciplina de Banco de Dados, configurando um espaço onde o professor e os alunos poderiam expor suas opiniões e discutirem sobre as atividades propostas.

A pesquisa segue em duas abordagens, sendo a primeira de cunho qualitativo, com a criação de um grupo fechado no Facebook denominado IFTO - Ensino médio/Banco de Dados, objetivando perceber o potencial colaborativo da referida ferramenta social. $\mathrm{Na}$ abordagem de cunho quantitativo, foram coletados dados a partir da estruturação e aplicação de uma pesquisa Survey com questionário eletrônico em escala likert, com objetivo analisar a postura dos alunos perante a produção colaborativa e reflexão crítica nas atividades do grupo, permitindo ainda compor uma análise quantitativa em relação ao uso do facebook.

Para coleta dos dados do questionário foram utilizadas as ferramentas do Google: o Google drive (permite o armazenamento de dados) e o Formulário google (permite fazer enquetes ou escalar equipes rapidamente com um simples formulário on-line) visando agrupar e obter a medidas estatísticas dos dados através de apresentação em gráficos, para a interpretação e análise. 
A análise de dados foi realizada através dos conteúdos e atividades desenvolvidas no grupo, além da exploração do material através da interpretação do conteúdo das mensagens.

\section{RESULTADOS E DISCUSSÃO}

Na utilização do Facebook como espaço de aprendizagem colaborativa, propôs-se complementar e dar contextualização somente ao conteúdo programático de Modelo Entidade-Relacionamento (MER) é um modelo de dados, utilizado para descrever banco de dados na fase conceitual do projeto, e o Diagrama Entidade-Relacionamento (DER) que é a representação gráfica do MER.

Após o direcionamento, foi criado o grupo no Facebook, o conteúdo do ambiente de aprendizagem foi construído aos poucos com as interações e discussões oriundas das atividades propostas, o professor manteve-se disponível mediando a ação colaborativa. Ao final das atividades dialogadas no Facebook, aplicou-se um questionário survey aos 24 alunos da turma e 15 responderam. Todos foram informados do caráter do trabalho.

Obteve-se resultados positivos como a interação dos alunos, as publicações de suas produções além dos comentários sobre os trabalhos produzidos, foi possível perceber a motivação sobre a temática, uma vez que os educandos superaram a suas limitações e se destacaram no papel de produtor. Conforme a Figura $\mathrm{n}^{\circ} 1$ e 2 a seguir, com recortes de atividades postadas pelos alunos do grupo de Banco de Dados no Facebook.

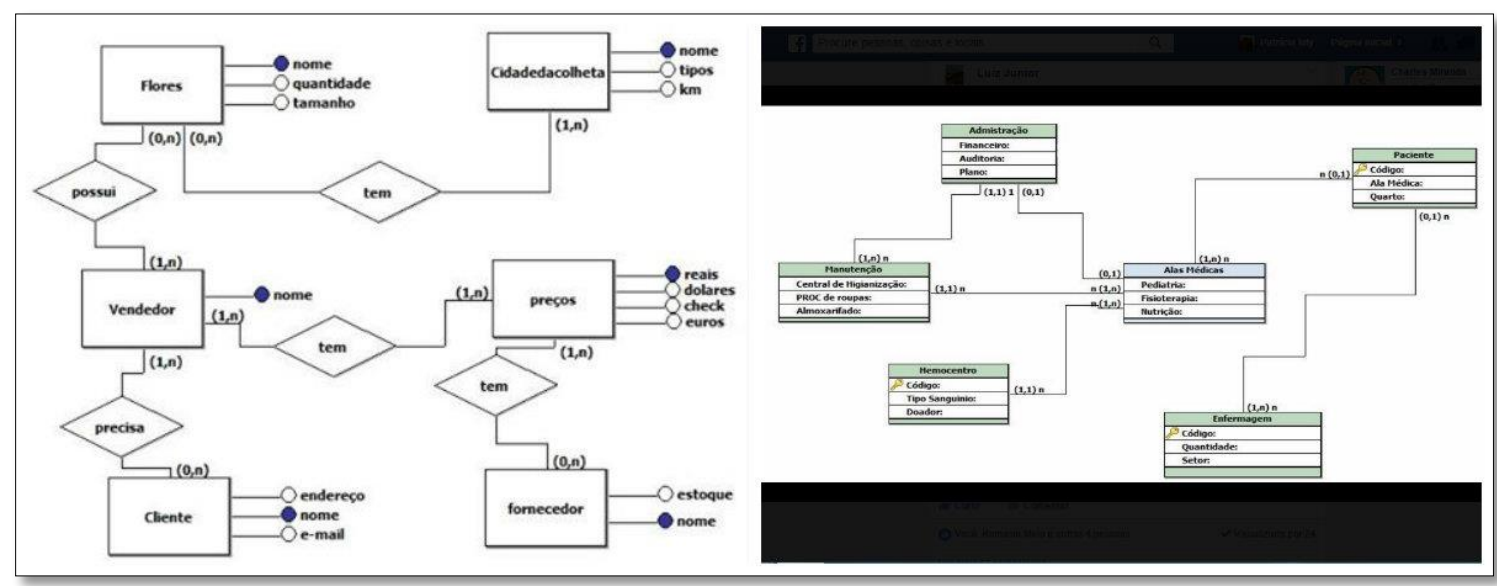

Figura 1 - Recortes de atividades produzidas pelos alunos. Fonte: Grupo de Banco de Dados no Facebook (2017). 


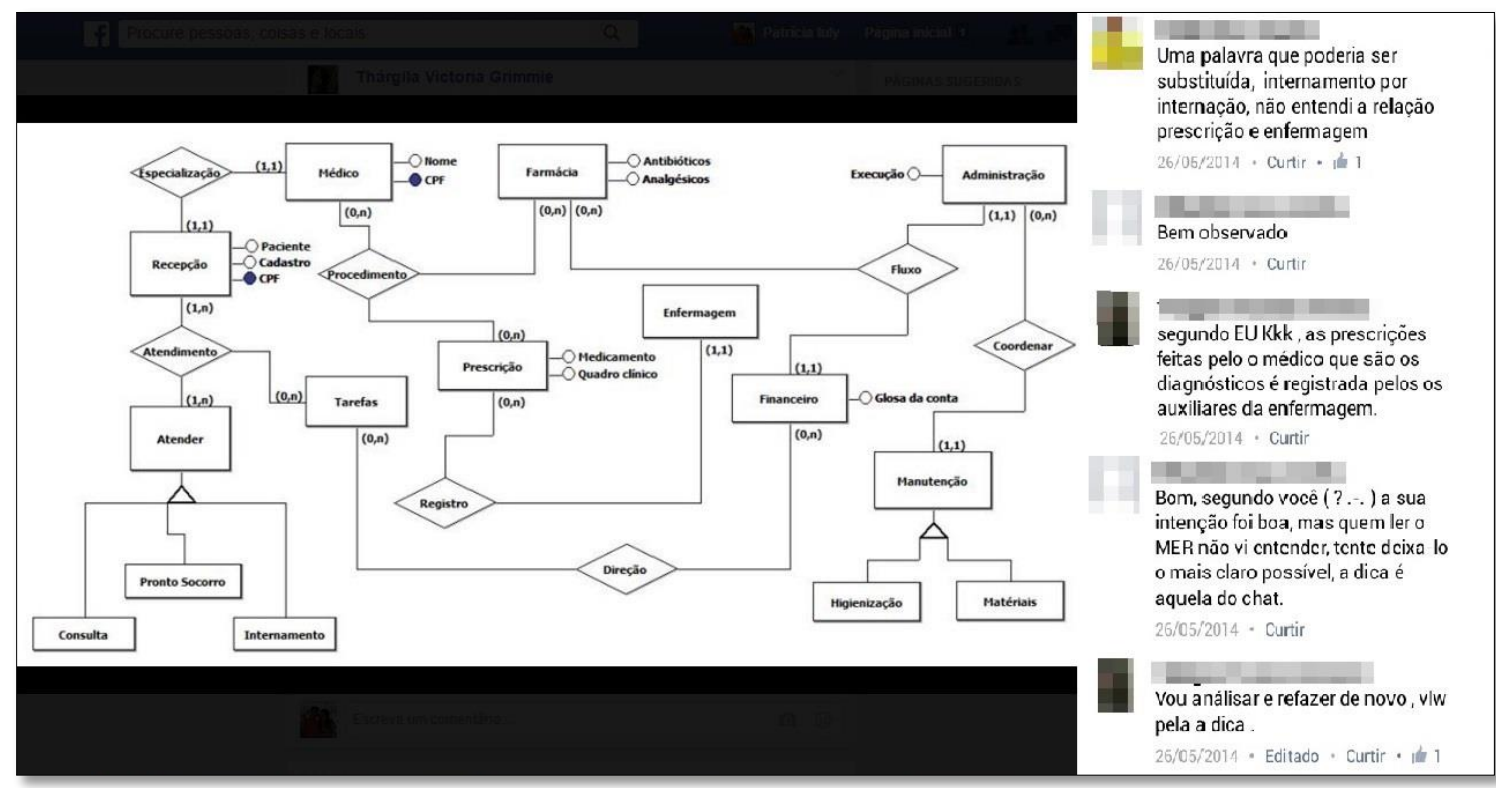

Figura 2 - Produção dos alunos.

Fonte: Grupo de Banco de Dados no Facebook (2017).

A seguir é analisado graficamente os resultados da pesquisa sobre a produção colaborativa mediada pelo objeto tecnológico em questão e a reflexão crítica nas atividades produzidas.

Em relação ao questionário, quando perguntados sobre os motivos de utilização das redes sociais, 46,67\% dos alunos responderam que usam para fins de "Lazer e entretenimento" e 40,00\% para "Comunicação", como mostra o Gráfico 1. Percebe-se que apesar das redes sociais possuírem características interativas e comunicativas, fazendo-se um importante instrumento de sociabilidade, podem também funcionar como elemento de distração e, portanto, apresentarão resultados negativos se seu uso no processo educativo não for planejado.

\section{Gráfico 1 - Motivação para utilizar a rede social.}

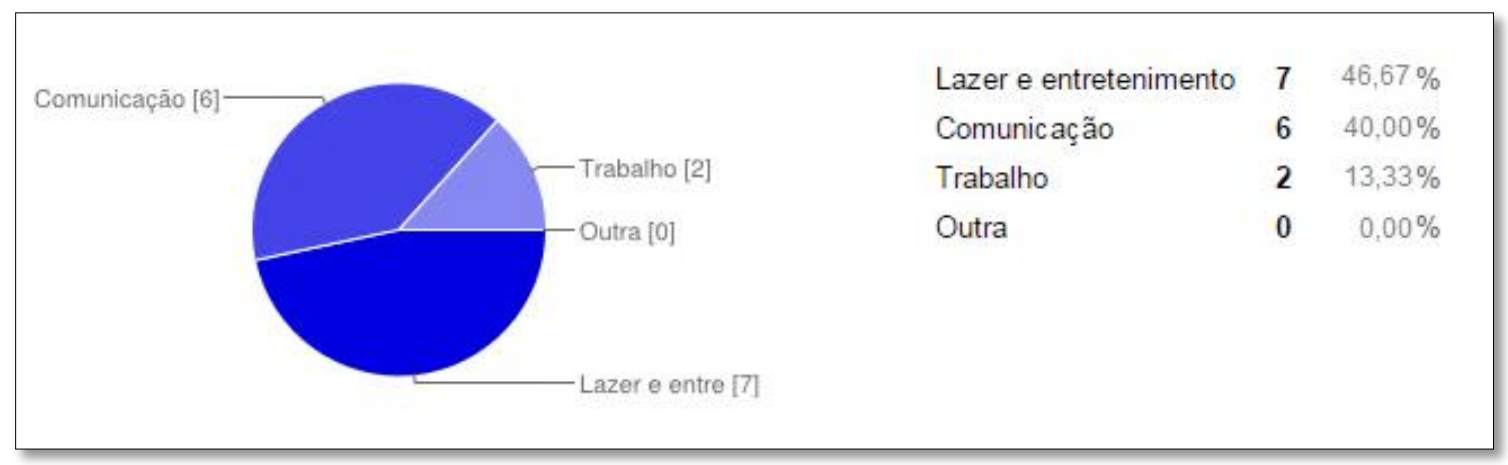

Fonte: Autor (2017).

Considerando a realidade em que os alunos estão inseridos, Minhoto e Merinhos sugerem que, "a instituição de ensino pode tirar proveito do interesse dos alunos pelas redes sociais e articular com os objetivos pedagógicos escolares, com isso conseguir que eles desenvolvam as competências previstas pelos programas das disciplinas (2011, p.25)". 
Essa contextualização do universo escolar com o universo pessoal do aluno, para Costa e Vilaça, "tem como finalidade permitir que a escola seja capaz de estender seu espaço para além de seus muros e cativar interesse de seus estudantes".

A introdução do Facebook como ferramenta de ensino é um grande desafio para escola, uma vez que se torna necessário haver primeiramente a aceitação por parte dos docentes e da instituição de ensino, seguida de planejamento e preparação para a aplicação. Contudo, o uso desta ferramenta não implica na exclusão ou substituição dos outros métodos e técnicas pedagógicas já existentes, mas sugere-se com esta que se possa acrescentar ao processo, mais um meio que seja benéfico ao aprendizado do aluno.

Quanto ao tipo de perfil de usuário 87\% se classificaram como "Participante", $13 \%$ como "Espectador" e nenhum se classificou como "Criador", como mostra a seguir no Gráfico 3.

\section{Gráfico 2 - Perfil de usuário na rede social}

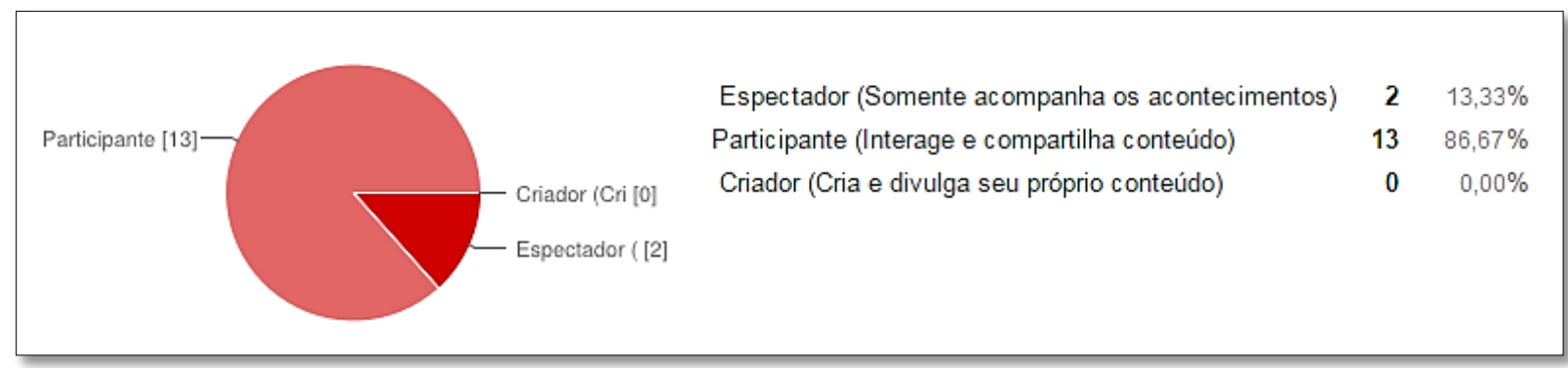

Fonte: Autor (2017).

Mesmo que a grande maioria em sua relação inicial com as redes sociais somente acompanha as informações e apenas interajam sobre o conteúdo dos outros e compartilham, constatou-se com a experiência na disciplina de Banco de Dados que as atividades propostas no Facebook exigiram uma mudança de postura de meramente usuário (participante/espectador) para a de criador (autor/ divulga o próprio conteúdo).

Sobre a afirmativa " $O$ professor promoveu a interação e colaboração entre os alunos, através das atividades propostas no Grupo", 40,00\% concordam plenamente, $46,67 \%$ concordam, enquanto que $13,33 \%$ discordam.

A partir do momento em que os alunos são envolvidos nos debates originados das atividades publicadas, todos são responsáveis pelo o que é produzido, sinalizando que o professor obtém bons resultados quando consegue promover o envolvimento dos alunos. 
Gráfico 3 - Interação e colaboração entre os alunos

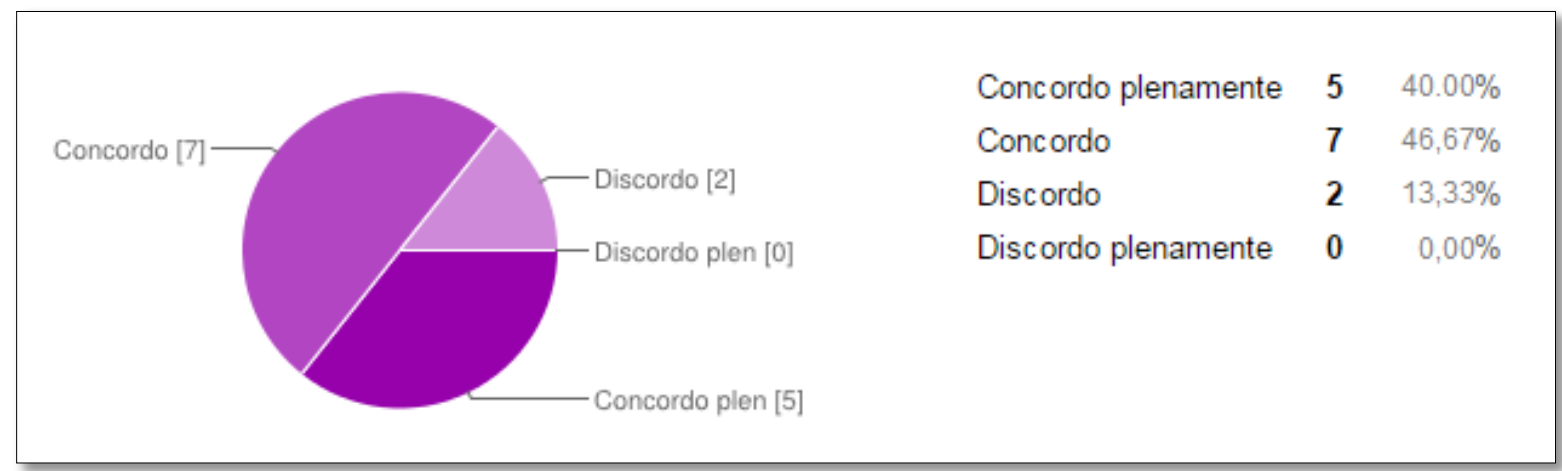

Fonte: Autor (2017).

A figura 3, vai ao encontro dos resultados do gráfico 3, ratificando que o professor desenvolve o papel de facilitador e dinamizador dos processos organizacionais do grupo e de encorajamento na participação e envolvimento na criação conjunta de ideias (DIAS, 2005).

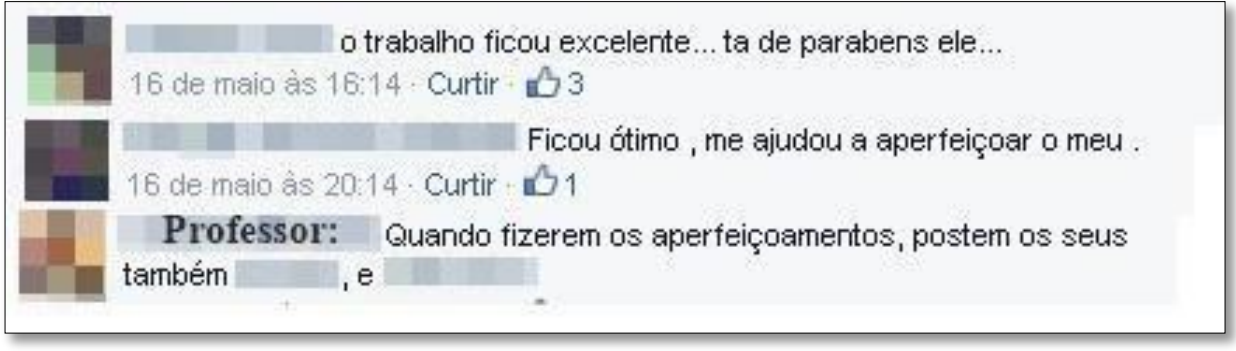

Figura 3 - O professor promove interação.

Fonte: Grupo de Banco de Dados no Facebook (2017).

Quanto a afirmativa "Desenvolvi e aprimorei a prática colaborativa, através das atividades propostas no Grupo", 33,33\% concordam plenamente, 40,00\% concordam, enquanto que $20,00 \%$ discordam e 6,67\% discordam plenamente.

Gráfico 4 - Desenvolvimento e aprimoramento da pratica colaborativa

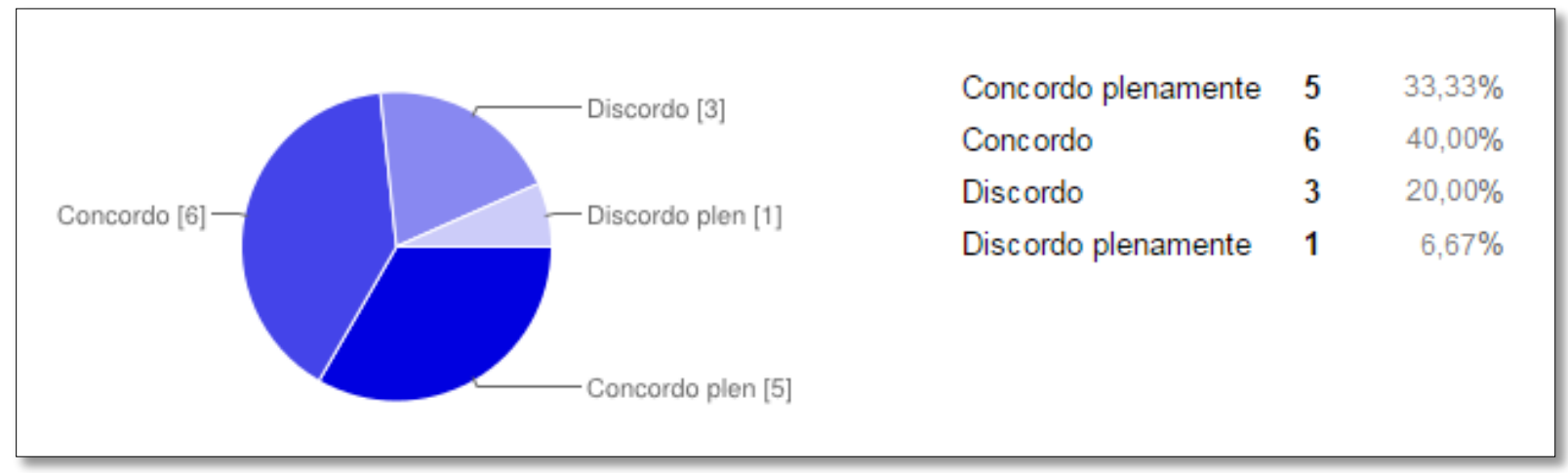

Fonte: Autor (2017).

Considerando que o trabalho colaborativo é evidenciado pela necessidade de colocar em prática atitudes de abertura, humildade, compartilhamento, respeito, aceitação, acolhimento, cumplicidade e compromisso (ALMEIDA E PRADO, 2003), tudo isso constatamos pela figura 2, dois exemplares das atividades que evidenciam que as práticas colaborativas foram desenvolvidas, no que diz respeito a livre participação, o compromisso com que os alunos contribuíram com aprendizado do outro. 
Desse modo, pode se afirmar que o uso do Facebook vai muito além do lazer e entretenimento, pois pode ser usado como recurso pedagógico facilitador da participação e interação, além de conduzir a uma construção crítica e reflexiva do conhecimento, em prol da aprendizagem do grupo da disciplina de Banco de Dados do Curso Técnico em Redes de Computadores no IFTO - Campus Araguatins.

\section{CONSIDERAÇÕES FINAIS}

A escola se depara com a situação desafiadora de aliar o quotidiano dos alunos com o contexto escolar, aproveitar o interesse dos alunos pelas redes sociais e usá-las como plataformas de aprendizagem, que propicie resultados, cujos mais significativos são as habilidades de discussão, autonomia dos alunos no processo educativo e as competências exigidas pelos programas das disciplinas.

Percebe-se que há obstáculos a serem superados, pois como qualquer recurso pedagógico que possa apresentar vantagens, porém também terá suas desvantagens, tudo irá depender da organização, do planejamento pedagógico e da metodologia trabalhada, do contrário será apenas um recurso alternativo para atrair a atenção dos alunos, sem garantir a qualidade do ensino.

Ao analisar o potencial do trabalho colaborativo mediado pela rede social Facebook, observou-se a conduta dos alunos perante a realização de atividades, aos poucos eles produziram um espaço de socialização, com interação, colaboração e comunicação entre aluno-aluno-professor, permitindo afirmar que a introdução de plataformas colaborativas como o Facebook, transformam as relações e possibilita a aprendizagem. Por fim, a pesquisa pôde apresentar um novo panorama que assume cada vez mais espaço, o Facebook no contexto educacional harmoniza-se com a evolução do educando, permitindo experimentar um sistema diferente do tradicional, tornando o processo de ensino-aprendizagem mais eficaz.

Adicionalmente sugere-se a utilização do Facebook como uma possibilidade de complementar as aulas e incentivar seu uso como meio de construção do conhecimento, não devendo ser uma obrigatoriedade imposta aos professores e a escola no processo educativo.

\section{REFERÊNCIAS}

ALMEIDA, Maria Elizabeth Bianconcini de; PRADO, Maria Elisabette Brito. Criando situações de aprendizagem colaborativa. IX Workshop de informática na escola WIE , p.53-60. 2003. Disponível em: <http://www.brie.org/pub/index.php/wie/article/ view/774>. Acesso em: 22 março 2017.

COSTA, Rosimeri Claudiano da; VILAÇA, Márcio Luiz Corrêia. O uso da rede social Facebook no ensino de Língua Portuguêsa. Revista Philologus, Ano 19, $\mathrm{N}^{\circ} 57$ Supl.: Anais da VIII JNLFLP. Rio de Janeiro: CiFEFiL, p.812-822, set./dez.2013. Disponível em: <http://www.filologia.org.br/revista/57supl/79.pdf >. Acesso em: $10 \mathrm{abr}$. 2017.

DIAS, Paulo. Processos de Aprendizagem Colaborativa nas Comunidades online. In Ana Augusta da Silva Dias e Maria João Gomes (Coords.), E-Learning para EFormadores. Guimarães: TecMinho/Gabinete de Formação Contínua, Universidade do Minho. 2005 Disponível em: <http://www.eadconsultoria.com.br/matapoio/biblioteca/ textos_pdf/texto26.pdf>. Acesso em: 10 abr. 2017. 
Comunidades de aprendizagem e formação on-line. Nova formação. Ano3, n.3, p.14-17. 2004. Disponível em:

<http://repositorioaberto.uab.pt/handle/10400.2/2178/>. Acesso em: 22 março 2017.

Comunidades de Conhecimento e Aprendizagem Colaborativa.

Comunicação apresentada no Seminário Redes de Aprendizagem, Redes de Conhecimento, Conselho Nacional de Educação, Lisboa, 2001. Disponível em:

<http://www.prof2000.pt/users/mfflores/teorica6_02.htm>. Acesso em: 22 março 2017.

FERREIRA, Gonçalo Costa. Redes sociais de informação: uma historia e um estudo de caso. Perspectivas em Ciência da Informação, v.16, n.3, p.208-231, jul./set. 2011. Disponível em: <http://www.scielo.br/pdf/pci/v16n3/13.pdf>. Acesso em: 10 abr. 2017.

MINHOTO, Paula; MEIRINHOS, Manuel. As redes sociais na promoção da aprendizagem colaborativa: um estudo no ensino secundário. Educação, Formação \& Tecnologias, v.4, n.2, p. 25-34, 2011. Disponível em: < http://eft.educom.pt/index.php/eft/article/view/227>. Acesso em: 15 abr. 2017.

MORAES, Emerson Evandro Martins. A escola do século XXI - As redes sociais em educação. 2011.19 f. Trabalho de conclusão de curso (Especialização em TIC aplicadas à educação) - Universidade Federal de Santa Maria (UFSM). Rio Grande do Sul. 2011. Disponível em: <http://docslide.com.br/education/a-escola-do-seculo-xxi-as-redessociais-na-educacao.html>. Acesso em: 18 abr. 2017.

RECUERO, Raquel. Redes sociais na internet. Porto Alegre, RS: Sulina, 2009. 192 p. (Coleção Cibercultura). 